\title{
A ENTREVISTA BIOGRÁFICA NA SOCIOLOGIA
}

THE BIOGRAPHICAL INTERVIEW IN SOCIOLOGY

\section{Baruc Correia Fontes ${ }^{1}$}

RECEBIDO: 10/03/2019 | ACEITO: 28/05/2019

DOI: $10.5902 / 2317175837238$

\section{RESUMO}

O presente artigo trata da entrevista biográfica como uma técnica de coleta de dados inserida dentro do método biográfico, que tem sua origem a partir de estudos inicialmente produzidos na Escola de Chicago. Neste sentido, apresentam-se reflexões teóricas com o objetivo de tecer análise acerca da metodologia biográfica no campo do quefazer sociológico. Dentro disso, o trabalho apresenta uma análise teórica acerca da importância da reflexão sobre o método a ser utilizado no campo das Ciências Sociais, levando em consideração os diferentes tipos de instrumentos de coleta de dados neste campo. É dada atenção especial à entrevista biográfica e as reflexões teóricas produzidas a seu respeito. Foi evidenciado que a entrevista biográfica agrega uma forma particular de entrevistar: o protagonismo é do entrevistado e não do entrevistador e o ponto de vista a ser vivenciado é o do entrevistado, contribuindo para a produção de conhecimento nas Ciências Sociais.

Palavras-chave: Entrevista biográfica; Metodologia qualitativa; Método biográfico; Ciências Sociais.

1 Mestre em Sociologia pela Universidade Federal de Sergipe. Docente do Centro Universitário UniAGES. 


\section{ABSTRACT}

This article deals with the biographical interview as a technique of data collection inserted within the biographical method, which has its origin from studies initially produced at the school of Chicago. In this sense, theoretical reflections are presented with the objective of analy zing the biographical methodology in the field of what to do(quefazer) sociological. Within this, the paper presents a theoretical analysis about the importance of the reflection on the method to be used in the field of Social Sciences, taking into account the different types of instruments of data collection in this field. Particular attention is given to the biographical interview and the theoretical reflections produced on it. It was evidenced that the biographical interview adds a particular form of interview: the protagonism is of the interviewee and not the interviewer and the point of view to be experienced is that of the interviewee, contributing to the production of knowledge in the Social Sciences.

Keywords: Biographical interview; Qualitative methodology; Biographical method; Social Sciences.

\section{Introdução}

A Sociologia é uma ciência que estuda os fenômenos sociais. Abarca, para isso, multiplicidade considerável de abordagens no que se refere à pesquisas. Caminhos e temáticas se cruzam para que se produza o conhecimento com a devida singularidade. No campo das metodologias existe uma disputa: metodologias quantitativas e qualitativas. Elas representam uma tradição e uma maneira de compreensão acerca das formas mais eficazes de se elaborar uma pesquisa. Essa disputa, nas ciências sociais, se dá entre metodólogos e sociólogos (BECKER, 1993).

O primeiro grupo compreende a pesquisa como um campo profícuo, no qual se pode julgar por meio da aplicação inflexível de alguma regra ou procedimento. Caracteriza-se, assim, um campo em que o material humano sofre profunda redução, já que, nesse caso, a produção da ciência necessitaria de imparcialidade, rigor e rigidez extremos para alcançar legitimidade. Na outra vertente, os sociólogos compreendem o ato da pesquisa como indissociável de análise histórica onde a problematização do julgamento humano dá o ritmo para o andamento das pesquisas (BECKER, 1993). Assim, o agrupamento de métodos é recomendado para que a ampliação das perspectivas através de mais de um método possa corroborar os resultados da pesquisa ou mesmo ajudar a construí-los, rompendo-se com a dicotomia neste campo (MINAYO, 2001; SOUZA e KERBAUY, 2017).

É a partir desse contexto que se pode discorrer sobre o cenário da pesquisa científica nas ciências sociais. Segundo Becker (1993), os metodólogos não deram a devida importância aos métodos qualitativos: métodos que não produzissem dados quantitativos por meio de algoritmos não poderiam ser válidos para eles. No entanto, a principal crítica de Becker (1993) não é ao modus operandi dos metodólogos, mas à máxima categórica do que seria a forma de produção da ciência, o que provoca o encarceramento do olhar sociológico e reduz a forma de construção e expansão da ciência sociológica. Essa concepção visa, exa-

RSh REVISTA SOCIAIS \& HUMANAS - VOL. 32 / № 3 - 2019 tamente, problematizar a construção e a utilização de métodos adotados pelos sociólogos, a mesma é de grande importância para o cenário da pesquisa, pois contribui para balancear a discussão no campo das ciências sociais, evidenciando, assim, não existir apenas uma forma de construção da ciência, mas vários caminhos que convergem - e divergem - em diferentes aspectos.

Minayo (2001) apresenta uma discussão crítica à respeito da metodologia. A autora explica que os dados coletados em pesquisas qualitativas e quantitativas não se opõem, mas se complementam, não dando espaço para entendimentos dicotômicos. Neste sentido, pensar diferentes métodos que congreguem a pesquisa qualitativa e quantitativa não se torna tarefa difícil. Günther (2006) apresenta um estudo acerca da congruência entre aspectos qualitativos e quantitativos nos diferentes instrumentos metodológicos, delineando que existem vantagens e desvantagens e que estas estão conectadas à obtenção dos dados e a maneira de utilizá-los, bem como das análises construídas.

No tocante à pesquisa qualitativa, objeto norteador desse trabalho, é importante dizer que a mesma não se constituiu ilesa à crítica, pelo contrário. Martins (2004) aponta para as principais críticas sofridas pela metodologia qualitativa, evidenciando que uma delas se refere a representatividade, entendida aqui sob a perspectiva de um cenário onde são analisados microprocessos que privilegiam estudos de caso e, portanto, não consegue ser representativo da sociedade em seu espectro mais amplo, o que aponta para dificuldades de generalizações. Uma segunda crítica elencada pela autora, diz respeito à ideia de subjetividade presente na pesquisa qualitativa, pois o pesquisador, ao se colocar nesse lugar onde afeta e é afetado pela pesquisa que executa, não conseguiria trabalhar aspectos da cientificidade e de neutralidade científica, o que resulta em uma falta de confiabilidade acerca dos dados coletados por meio da pesquisa qualitativa.

Nesse sentido, o trabalho estrutura-se da seguinte maneira: inicialmente discorre-se sobre a sociologia reflexiva enquanto campo necessário para a discussão travada entre teoria e metodologia, pensando numa intersecção inerente nesta esfera. De outra maneira, a proposta segue apresentando as diversas possibilidades de entrevistas nas ciências sociais, partindo-se a pensar sobre a entrevista biográfica como instrumento capaz de gerar uma reflexão à respeito do próprio quefazer ${ }^{3}$ sociológico, ou seja, a tarefa da sociologia enquanto campo de trabalho teórico e prático. Para tal feito, consideram-se as perspectivas teóricas de Becker (1993) e Bourdieu (1997) como instrumentos capazes de produzir lugares reflexivos sobre a metodologia biográfica. Discute-se aqui, portanto, a possibilidade de ampliar o debate do campo metodológico nas ciências sociais, por meio da explanação de um método que traga reflexividade sobre os próprios resultados produzidos, questionando e, ao mesmo tempo, buscando produzir novos espaços de reflexão por meio da técnica da entrevista biográfica.

Quefazer indica a proposta de pensar a prática desta profissão e as maneiras como esta se materializa. 


\section{Por uma sociologia reflexiva}

Para se entender a entrevista biográfica em seu conjunto de possibilidades que serão apresentadas ao longo deste trabalho, é necessário, antes, pensar a sociologia como uma disciplina reflexiva, que requer a compreensão de que teoria e método não devem estar em campos opostos, mas devem ser percebidos num processo relacional de complementaridade. Bourdieu (1998) postula essa questão da seguinte forma:

A divisão <<teoria >> / < <metodologia >> constitui em oposição epistemológica uma oposição constitutiva da divisão social do trabalho científico num dado momento (como a oposição entre professores e investigadores de gabinetes de estudos). Penso que se deve recusar completamente essa divisão em duas instâncias separadas, pois estou convencido de que não se pode reencontrar o concreto combinando duas abstrações. (p. 24 )

O autor provoca uma reflexão sobre a impossibilidade de pensar a construção de hipóteses empíricas sem pressuposições teóricas, já que a empiria demanda um processo de reflexividade para que seja possível tratá-la como prova concreta de alguma coisa. Nesse sentido, a ideia de pensamento dedutivo corrobora à construção de uma Sociologia reflexiva, pois considera as teorias ou leis genéricas acerca de determinado assunto, avaliando-as como de fundamental importância para se chegar a alguma conclusão no processo de realização de uma pesquisa; sendo a confrontação das premissas teóricas um instrumento que possibilita a análise de dados empíricos (BENEDICTO et al 2012). Tal concepção não continua distante da ideia de Bourdieu (1998), pois o mesmo afirma que é somente a partir do levantamento de hipóteses fundamentadas em um conjunto de pressupostos teóricos, que os dados empíricos farão sentido e se tornarão evidência de algo.

É importante reiterar que tal reflexividade não poderá ser marcada pela ideia monoteísta de um método como única forma possível de compreensão de fenômenos. Pelo contrário, é preciso romper com essa lógica e entender que a junção de diferentes métodos pode agregar reflexividade e criticidade aos trabalhos produzidos. Becker (1993) aponta para o "mosaico", ideia de agregar diferentes métodos, como um caminho possível para a compreensão de um quadro de pesquisa, ou seja: a partir da inserção de diferentes métodos, as peças das pesquisas tenderiam a ficar mais compreensíveis, tendo cada uma, funções diferentes para agregar ao todo.

A ideia do mosaico como um método possível de pesquisa se contrapõe, mais uma vez, à ideia defendida pelos metodólogos, em que uma linha metodológica é compreendida como fundamental para o alcance dos objetivos de cientificidade, o que acaba por inibir reflexões à respeito do problema de pesquisa levantado e dando um tom descritivo e pouco analítico às suas análi- ses. Há um curioso anseio nos metodólogos em anunciar uma maneira "certa" de realizar pesquisas. Becker (1993) defende o caminho contrário, partindo do princípio de que acreditar em uma verdade absoluta ou metodologia "correta" para realização de pesquisas, pressupõe que existam metodologias erradas, o que leva a uma polarização entre pesquisadores e consagra a ideia de monoteísmo no campo das ciências sociais, criticada pelo próprio autor.

É importante, portanto, romper com a lógica metodológica sem reflexividade e incorporar uma postura crítica para a construção de uma sociologia reflexiva. Bourdieu (1998) apresenta uma discussão pertinente acerca da constituição do objeto e da dualidade entre metodólogos e sociólogos:

Construir o objecto supõe também que se tenha, tos, uma postura activa e sistemática. Para romper com a passividade empirista, que não faz senão ratificar as pré-construções do senso comum, não se trata de propor grandes construçōes teóricas vazias, mas sim de abordar um caso empirico com a intençáo de construir um modelo - que náo tem necessidade de rigoroso - de ligar os dados pertinentes de tal modo que ser funcionem como um programa de pesquisas que põe questões suncionem como um programa de pesquisas que poe questoes resumo, trata-se de construir um sistema coerente de relacões, que deve ser posto à prova como tal. (p. 32)

Mais uma vez, questiona-se a necessidade de algoritmos para corroborar pesquisas. Bourdieu (1998) incentiva, como demonstra o fragmento acima um posicionamento crítico que leve em consideração o sistema relacional entre teoria e empirismo.

Esse posicionamento trata a pesquisa sociológica como algo relacional não univoca nem reducionista. É preciso levar em séria consideração que é impossível pôr em suspenso todas as ideologias que permeiam o pesquisador como um ser social. É impossível realizar a pesquisa como algo isolado, que caiba em um laboratório. A pesquisa só acontece de modo reflexivo quando o sociólogo se dá conta desse processo de retroalimentação entre o mundo social que ele habita e o mundo científico da sua pesquisa e, também, de como é impossível anulá-los e torná-los independentes. Ter consciência disso, se torna mais importante do que tentar controlar esses processos por meio da defesa de uma metodologia tecnicista, que produza um estatuto de verdade que seja mais aceito pelo modo rígido e imparcial, como o pesquisador trata a execução de sua pesquisa (BOURDIEU, 1998).

Minayo (2001) corrobora a perspectiva de Bourdieu (1998) ao declarar que a ciência é comprometida, pois ela se materializa através de pessoas, que apresentam "interesses e visões de mundo historicamente construídas, embora suas contribuições e seus efeitos teóricos e técnicos ultrapassem as intenções do seu desenvolvimento" ( p. 14). Neste sentido, não é possível cravar 
a existência de uma ciência que não leve em consideração, tais aspectos na constituição do seu modus operandi.

De outro modo, é importante tratar da imaginação sociológica como instrumento capaz de promover essa conversão de um olhar técnico para um olhar sociológico. Mills (1980) trata desse dispositivo como essencial para a execução de uma pesquisa sociológica. É por meio do processo reflexivo acerca de teorias e métodos que permeiam a imaginação do sociólogo, que possível chegar em um estado de reflexividade. Esse estado auxilia no entendimento do objeto sociológico propriamente dito. De outro modo, não seria possível apresentar um trabalho sociológico em sua "inteireza", que leve em conta o processo relacional e suas implicações.

Como se pode perceber, o processo de reflexão acerca das possibilidades de entendimento sobre métodos de pesquisa, só se torna possível quando se rompe epistemologicamente com uma forma convencional de produção da ciência e se instaura um novo olhar, um olhar sociológico, produzido por meio da conversão da visão do mundo social no qual o sociólogo habita. Mais uma vez, Bourdieu (1998) coloca a importância dessa ruptura, entendendo que uma das tarefas em ciência social é estabelecer no cerne da prática científica o que ele chama de conversão do pensamento, passando a trabalhar, a partir desse conceito, a deformação das coisas, das ideias pré-concebidas, proporcionando a ruptura com a ordem social e consequentemente com o que a sustenta.

Minayo (2001) apresenta discussões no campo do positivismo e da regulação de uma sociologia compreensiva, entendendo que esta segunda possibilidade, da compreensão no campo das ciências sociais, coloca em evidência a necessidade de construir espaços de compreensão da realidade humana, sendo este fato indissociável da pesquisa em ciências sociais. Esta perspectiva adota a subjetividade humana como caminho inerente às leituras e análises sociais.

Ou seja, há que se pensar no quefazer sociológico como uma possibilidade de manter um olhar crítico à respeito do mundo que o cerca, de como ele constrói e é construído. Saber disso é fundamental para a produção de uma sociologia reflexiva.

\section{Refletindo sobre o método}

A importância de construir um método que esteja embasado numa reflexão teórica é a premissa do quefazer do sociólogo dentro da pesquisa científica. A entrevista biográfica, nesse sentido, entra como uma técnica que apresenta uma reflexão teórica e que, portanto, exige constantes atualizações sobre a maneira como está delineada.

Em contraponto ao modo positivista utilizado pelos metodólogos, a pesquisa qualitativa, por meio da entrevista biográfica, deseja expor o subjetivo como fonte de obtenção de dados empíricos, produzindo uma sociologia compreensiva, calcada na corrente do interacionismo simbólico de George He- bert Mead, que exerceu forte influência sobre a Escola de Chicago, lugar onde proliferou a utilização de métodos qualitativos. Sobre o modo como o interacionismo simbólico percebe a pesquisa científica, Goldenberg (2004) expressa:

O interacionismo simbólico destaca a importância do indivíduo como intérprete do mundo que o cerca e, consequentemente, desenvolve métodos de pesquisa que priorizam os pontos de vista dos indivíduos. O propósito destes métodos é compreender as significações que os proprios indivíduos poem em pratica para construir seu mundo social. Como a realidade social só aparece sob a forma de como os indivíduos vêem este mundo, o meio mais adequado para captar a realidade e aquele que propicia ao pesquisador ver o mundo através "dos olhos dos pesquisados". (p. 27)

Essa reflexão acerca da percepção da pesquisa científica aponta, portanto, para o interacionismo simbólico e a Escola de Chicago como espaços de reflexão sobre a pesquisa qualitativa. No que concerne ao estatuto da entrevista dentro dos campos de pesquisa, é importante ressaltar um dado: a entrevista na sociologia, apesar de ser percebida por alguns como um instrumento da pesquisa qualitativa, também pode ser utilizada para a pesquisa quantitativa. Boni e Quaresma (2005) enfatizam a busca por dados subjetivos, a partir do próprio mecanismo da entrevista e objetivos, obtidos também "através de fontes secundárias como censos" (p. 72), por exemplo, como sendo características dessa técnica.

A seguir apresentam-se alguns tipos de entrevistas que a Ciência Sociológica tradicionalmente tem utilizado para coletar dados e produzir conhecimento a partir disso. Os tipos de entrevistas não abarcam a multiplicidade de modelos vigentes, esta também não é a pretensão desse texto, mas sim, apontar algumas possibilidades dentro desse campo, cada vez mais diverso.

Um dos tipos de entrevista na pesquisa das ciências sociais é a entrevista estruturada. Ela tem como característica principal a utilização de um quadro fechado de perguntas, sobre o qual não há grandes variações. Pode ser desenvolvida por meio de questionários ou formulários e o pesquisador faz uma intervenção mínima para aplicá-lo - diferentemente da análise, que requer uma visão que vá além dos dados quantitativos (GIL, 2008).

A entrevista semiestruturada se caracteriza por lidar com um roteiro que não é fixo. Este roteiro é capaz de introduzir novas perguntas a partir do contato com o entrevistado. Exige do pesquisador um nível de atenção maior para entender o momento ideal da introdução de um tema ou uma pergunta. Esse tipo de entrevista é recomendada quando se deseja direcionar assuntos a fim de alcançar objetivos específicos. Vai, portanto, ao encontro do que a pesquisa qualitativa enseja. Boni e Quaresma (2005) falam dela relatando que "quanto menos estruturada a entrevista maior será o favorecimento de uma troca mais afetiva entre as duas partes" (p. 75). Isso corrobora como fica explícito, a ideia de uma sociologia reflexiva. 
Outro tipo de entrevista é a entrevista aberta, caracterizada pelo perfil exploratório, onde o pesquisador escolhe um tema central para a pesquisa e a mesma acontece de maneira mais fluída, sem um roteiro prévio, sendo o pesquisador, nesse sentido, exigido muito mais do que em outros tipos de entrevistas. A interferência do entrevistador, contudo, deve ser calculada, priorizando o espaço do entrevistado e interferindo apenas para ampliar o entendimento sobre algum trecho da fala ou para direcionar o tema a ser conversado (BONI; QUARESMA, 2005).

A entrevista projetiva - mais um tipo - é caracterizada pela utilização de recursos visuais - fotos, pranchas, vídeos - que objetivam enriquecer o processo de pesquisa, evitando também a utilização de respostas diretas. Outro objetivo é enriquecer o processo de coleta de dados por meio de achados em profundidade acerca do entrevistado ou grupo (BONl; QUARESMA, 2005). A entrevista exploratória, por sua vez, tem uma definição mais sofisticada. Quivy e Campenhoudt (2005) a apresentam como sendo interessante para aqueles pesquisadores que ainda não constituíram a sua "questão", servindo para ampliar a reflexão e amadurecer a problemática. Esse tipo de entrevista é baseada na abordagem de Carl Rogers (1973), centrada na pessoa, ou seja: prioriza o direcionamento que o entrevistado deseja dar, deixando-o livre para falar, porém, tendo como finalidade encontrar indícios reflexivos, ideias e hipóteses para o desenvolvimento do trabalho.

A "história de vida" também é um tipo de entrevista utilizada com o objetivo de narrar as experiências dos entrevistados retomando, em retrospectiva, a trajetória de vida dos sujeitos e fornecendo, assim, diversas informações a respeito desse próprio sujeito. Boni e Quaresma (2005) apontam para a relevância da história de vida enquanto uma ferramenta de entrevista em profundidade, onde o pesquisador poderá interagir com o entrevistado. Além disso, confirma que "sua principal função é retratar as experiências vivenciadas por pessoas, grupos ou organizações" (p. 73), além de contribuir para o processo de retrospectiva das vivências do sujeito, o que permite acessar pensamentos por vezes reprimidos.

Na construção de uma crítica à história de vida, Bourdieu (1996) questiona a ideia de linearidade, entendendo que o entrevistado selecionará os pontos que deseja incluir no seu relato, tornando assim a história de vida uma versão contada sob sua perspectiva, favorável, que não abrange a totalidade da sua trajetória e nem obedece a uma ordem cronológica. No entanto, Becker (1993) aponta a importância dessa técnica para a confirmação do protagonismo do sujeito, sobre sua própria trajetória ao nomear os fenômenos da "histó ria própria da pessoa" (p. 103), como um processo positivo onde se prioriza a visão dos entrevistados sobre as interpretações acerca da sua própria história.

Uma distinção importante, é apontar que a história de vida consiste em uma técnica de entrevista empregada pelo cientista social, que focaliza os aspectos do relato de um sujeito acerca de sua existência por meio de uma cronologia, diferente da ideia de biografias, onde se insere o método biográfico, em que a história do sujeito é escrita sem a intervenção do pesquisador, dando-lhe o protagonismo acerca dos relatos obtidos (GUÉRIOS, 2011).

Diante da multiplicidade de tipos de entrevistas, se torna necessário considerar que cada uma apresenta suas peculiaridades a partir da concepção teórica adotada. Com efeito, é importante lembrar que o objetivo deste trabalho é tecer análises acerca do método biográfico, mais precisamente acerca da entrevista biográfica. Pensando nisso, aborda-se na seção seguinte, de maneira específica este tipo de entrevista, possibilitando delinear aspectos singulares à respeito da mesma.

\section{A entrevista biográfica}

O método biográfico nasce na década de 1920 na Escola de Chicago, frente aos métodos positivistas vigentes naquela época que endossavam um discurso quantitativo à respeito do modus operandi da pesquisa sociológica. No entanto, diante do avanço da corrente funcionalista, que se tornou hegemônica entre os anos 40 e 60 , o método biográfico perdeu força, retornando no período de 1970 em diante, a partir da criticidade de alguns autores diante dos métodos sociológicos tradicionais (GUÉRIOS, 2011). O método biográfico sofreu duras críticas mesmo após essa estabilização. Bourdieu (2006) e seu texto "A ilusão biográfica" marcaram esse momento. A crítica é dirigida ao fato de apenas uma perspectiva ser considerada sobre uma determinada trajetória de vida; a do próprio sujeito que narra - o que o coloca em uma posição de ideólogo.

Esse método é permeado por duas perspectivas que corroboram para sua concretização: os materiais colhidos por meio de fontes primárias e fontes secundárias (OLIVEIRA et al., 2013). Inicialmente, o método biográfico pode colher informações por meio de documentos, cartas e livros de memórias. Dessa forma, não depende da memória dos sujeitos para a pesquisa. A fonte secundária é a entrevista, em que o sujeito narra sua história, sem compromisso com a linearidade, apresentando pontos que considera relevante e ocultando pontos desnecessários.

Como diferença fundamental da história de vida proferida por Becker (1993), a entrevista biográfica prioriza o "corte sobre o fenômeno investigado, nas suas relações sociais ao longo da história já vivida e da que está por vir, como antecipação do futuro" (MATTOS, 2015, p. 551). Não é um encarceramento da história do sujeito, um ponto de chegada, mas sim uma forma de compreensão acerca de um processo não-linear.

Nesse sentido, como argumento contra a legitimidade da história de vida, Bourdieu (1996) cita Alain Robbe-Grillet. Ele diz que, "o real é descontínuo formado por elementos justapostos sem razão, cada um é único, e tanto mais difíceis de entender porque surgem sempre de modo imprevisto, fora do 
propósito, de modo aleatório" (p. 76). Ou seja, não há como reconstituir uma história de vida cuja essência seja resgatada linearmente, pois a descontinuidade da vida é transportada para os relatos de maneira incontornável. Essa perspectiva do método biográfico corrobora a noção de ilusão biográfica, bem colocada por Bourdieu (1996), onde ele trata da problematização de pensar a entrevista biográfica como fonte de um processo linear, que busca encontrar razão, sentido e, sobretudo, a percepção de que tais características fogem ao controle dos processos subjetivos que permeiam a entrevista qualitativa.

Nesse ponto, não há como tratar a entrevista biográfica como um instrumento isolado do contexto social dos sujeitos que dela participam. É necessário entender que a composição da trajetória deles é permeada por componentes externos. Mattos (2015) diz que "é importante salientar que a entrevista biográfica é um método de trabalho que leva em conta a seguinte premissa: 0 sujeito entrevistado possui uma subjetividade, a qual é constitutiva da sociedade e, portanto, construída coletivamente" (p. 551). Assim, que o sujeito fala durante a entrevista deve ser inserido no contexto social ao qual pertence. A análises não podem ser deslocadas disso, do contrário os resultados podem se afetados. É importante revisitar a todo tempo a construção da narrativa do sujeito e desenvolver a criticidade para que os resultados encontrados ganhem cientificidade e legitimidade.

É necessário entender, também, que a entrevista biográfica se insere no grupo de métodos qualitativos e que, portanto, corrobora a evocação do subjetivo como ponte para os achados que serão traduzidos em narrativas. Como tal, interpreta-se e reinterpreta-se constantemente por meio do posicionamento crítico frente aos dados obtidos, tanto na forma de consegui-los, quanto na maneira como é pensado. Esse é um método, portanto, que apresenta rigor metodológico e que tenta capturar dos sujeitos uma versão de sua trajetória que não seja necessariamente linear, mas que apresente a espontaneidade que fará prevalecer e que, por sua vez, agregará aos resultados encontrados (MATTOS, 2015)

\section{Reflexões sobre a entrevista biográfica}

Refletir a respeito do método biográfico é necessário, pois a sua construção histórica é marcada por uma trajetória em acordo com uma sociologia reflexiva, que pensa o método como algo além de dados sem sentido ou propósito. A proposta da entrevista biográfica está atenta às trajetórias narradas sem "comprar" determinada versão como única e conclusiva possibilidade de se narrar uma trajetória no campo da pesquisa científica. Bourdieu (1997) aponta sobre isso ao tratar da "reflexividade reflexa" na condução de uma entrevista: permite perceber e controlar no campo, na própria condução da
entrevista, os efeitos da estrutura social na qual ela se realiza. entrevista, os efeitos da estrutura social na qual ela se realiza.
(...) Principalmente esforçando-se para fazer um uso reflexivo dos conhecimentos adquiridos da ciência social para controlar os efeitos da própria pesquisa e começar a interrogação já dominando os efeitos inevitáveis das perguntas. (p. 694)

É importante estar atento à estrutura que sustenta a fala dos sujeitos, sabendo que ela é permeada por diversos fatores, sendo, portanto, impossível unificar em um discurso a trajetória completa de um sujeito. Estar em estado de reflexividade reflexa colabora para essa concepção.

A partir disso, e/ou através disso, é necessário estar atento também para os direcionamentos práticos que estruturam a entrevista biográfica. Como o objeto de estudo do método biográfico é o individuo em sua singularidade, deve haver espaço na entrevista para que a subjetividade venha à tona. Esta última necessita do que Bourdieu (1997) chama de uma comunicação não-violenta, que tem como característica a tentativa em conhecer os efeitos que a relação estabelecida entre pesquisador e pesquisado produzirá, ou poderá produzir, buscando compreender o sentido que o pesquisado extrai da situação, da pesquisa e o que ele vem estabelecer como relação a partir disso, culminando, finalmente, no entendimento das razões que o levaram a participar da entrevista.

Delory-Momberger (2012) em seu artigo intitulado "Abordagens metodológicas na pesquisa biográfica" aponta para um importante recorte na condução da entrevista biográfica; ela fala em seguir os atores - o que contrapõe a ideia da entrevista clássica, onde entrevistador pergunta e entrevistado responde, obtendo êxito quando essa dinâmica funciona. No entanto, na condução da entrevista biográfica, é importante seguir os atores no sentido de escutar quais os seus anseios, seus questionamentos quanto ao passado, presente e futuro.

Desse modo, os papeis tendem a se inverter: "em se tratando de seguir os atores, o narratário não pode mais anteceder o narrador, só pode correr atrás dele e tentar ficar o mais perto possível nas sinuosidades, nas bifurcações, nas rupturas dos seus caminhos e dos seus desvios, sem nunca ultrapassá-lo" (DELORY-MOMBERGER, 2012, p. 528). Tal concepção contribui para construir novos lugares de narratário e narrador, compreendendo que este segundo tem o papel central na entrevista e que colabora, antes de tudo, para a formulação das perguntas: uma vez que desenvolve sua trajetória de vida, tais perguntas são também suas inquietações. Estar atento para essa diferente configuração é de fundamental importância ao pesquisador biográfico.

Em seu aspecto historiográfico, o método biográfico tem se firmado na construção de trajetórias de sujeitos como interlocutores de uma concepção singular que reflete a pluralidade da sociedade vigente. Por isso, no campo da análise, o pesquisador deve ter atenção redobrada para identificar as nuances do discurso em cada ponto, para impedir seu deslumbramento acrítico. É necessário estar atento à narrativa e sua reconstrução, bem como ao modo 
de desenvolvimento da análise dos dados obtidos (NICO, 2012). Ou seja, só se pode compreender verdadeiramente tudo que é dito, quando o pesquisado aprende a analisar as relações entre as estruturas objetivas, presentes e passadas, que são localizadas no discurso dos sujeitos (BOURDIEU, 1997).

A maneira como se constitui a entrevista biográfica no campo empírico não está dissociada da reflexão teórica acerca do método biográfico. É preciso reconhecer as potencialidades e limitações de aplicabilidade dessa ferramenta. Reforçando o que foi discutido anteriormente, é importante dizer que Bourdieu (1996) contribuiu para questionamentos acerca de como o método biográfico pode se transformar em uma ilusão biográfica, pois acreditar em uma narrativa uniforme, seria admitir que a vida narrada pelo sujeito é uma história coerente. Bourdieu (1996) diz que não é. Tal concepção põe em evidência a luta pela aceitação de uma fundamentação epistemológica que se materializa por meio de diferentes possibilidades de aplicação do método e consequentemente das análises extraídas a partir disso.

Potencialmente, a entrevista biográfica tem se configurado como uma possibilidade de construir novos caminhos no que se refere à concepção acerca do que seja método qualitativo e seus achados, bem como no tocante ao campo das entrevistas. Ela tira o pesquisador do lugar comum e exige dele uma forma rebuscada de aplicação e de análise. Essa concepção de entrevista exige que o percurso de aplicação metodológica seja pautado em princípios que norteiem o pesquisador a desenvolver um trabalho diferenciado, em que as perguntas do entrevistado tenham mais importância que suas respostas. Isso corrobora para a facilitação do pesquisador enquanto entrevistador, pois não dependerá dele o andamento e/ou condução da entrevista, mas do percurso/ trajetória de vida do pesquisado, suas idiossincrasias e o modo como ele as expõe. Por outro lado, o pesquisador estará atento em como a narrativa biográfica reflete o modo de vida da sociedade pesquisada. Goldemberg (2004) aponta para isso quando diz que "Se cada indivíduo singulariza em seus atos a universalidade de uma estrutura social, é possível ler uma sociedade através de uma biografia, conhecer o social partindo-se da especificidade irredutível de uma vida individual" (p. 37)

Há, no entanto, desafios que compõem essa abordagem metodológica. Um deles é conseguir dar conta da grande quantidade de material de dados coletados, possibilitando o acesso às informações que são essenciais na construção da análise. Para isso, o pesquisador deverá estar em relativa imersão para elaborar um olhar crítico a respeito dos dados coletados. É necessário ao pesquisador a capacidade de diferenciar o conhecimento vivido do conhecimento real. O pesquisado trará um emaranhado de informaç̃es e caberá ao pesquisador confrontá-las, buscando entender a forma como o entrevistado compreende sua trajetória (OLIVEIRA et al, 2013). Esse olhar leva ao entendimento de que existe a necessidade constante de analisar a realidade por meio dos acontecimentos simples do cotidiano, das experiencias singulares que são apresentadas pelo narrador - o que não se constitui, certamente, em uma tarefa fácil.

Joga a favor dessa abordagem, a possibilidade de compreender - ou apenas tentar compreender - a multiplicidade de informações que circundam a vida dos sujeitos pesquisados. É possível, também, transportar tais concepções para a compreensão de estruturas macro que sustentam esse discurso e que compõem sua trajetória não-linear e perfazer, assim, uma estrutura consistente de compreensão e análise. Mattos (2015) aponta que a "entrevista biográfica é um método de trabalho estruturado que leva em conta a seguinte premissa: o sujeito entrevistado possui uma subjetividade, a qual é constitutiva da sociedade e, portanto, construída coletivamente" (p. 551). Esse é o ponto primordial para entender e situar a entrevista biográfica como um vetor produtor de história, subjetividade e, é claro, conhecimento. Seus objetivos e funções dentro do campo das pesquisas qualitativas em ciências sociais, tanto mais nítidos ficam, quanto mais ficam evidentes suas estruturas de elaboração e re-elaboração internas, conectadas com a realidade histórica e social dos sujeitos que dela participam.

\section{Considerações finais}

O trabalho de reflexão aqui desenvolvido defende o modelo da entrevista biográfica inserida em um método qualitativo como importante contribuição crítica das ciências sociais. Empoderar e estimular a realização de pesquisas qualitativas, a utilização do método biográfico e da técnica de entrevista biográfica, como formas renováveis de colher informações e compreender os fenômenos sociais, é o ponto central desse trabalho. Não se quer dizer, no entanto, que a pesquisa quantitativa não dê conta desses fenômenos. Mas busca-se ressaltar, sobretudo, a importância de quebra do monopólio epistemológico que vigora e valida o estatuto de verdade nas pesquisas científicas.

Neste sentido, as contribuições da entrevista biográfica agregam uma forma diferente de entrevistar: o protagonismo é do entrevistado e não do entrevistador, e o ponto de vista a ser vivenciado é o do entrevistado. O que mais interessa neste contexto de aferição é ouvir o que o entrevistado tem a dizer em toda a sua singularidade, como alguém inserido em um contexto social, mas que também atua para modificá-lo.

De outro modo, a entrevista biográfica, tal qual salienta Bourdieu (1996), pode se tornar um instrumento de coleta de dados pautado pela ilusão de reconstituição global da trajetória dos sujeitos, fato esse criticado pelo autor. O que interessa pensar nesse aspecto, é a reflexão a respeito das limitações impostas ao método biográfico, enquanto reconstituição linear e coesa da vida dos sujeitos.

Dessa forma, o grande desafio é administrar a aplicação da entrevista biográfica e compreender os resultados produzidos de uma forma não-cris- 
talizadora, não-convencional, não-linear que possibilite, enfim, contribuir de maneira efetiva para o avanço e aprimoramento das pesquisas qualitativas nas ciências sociais e também na produção de conhecimento de maneira geral seja como fonte inspiradora, seja como referência epistemológica. Tal estudo necessita encontrar eco no campo das ciências sociais, compreendendo que a pesquisa sobre método biográfico e entrevista biográfica aponta para a necessidade de construir novas possibilidades de uso e interpretação de métodos qualitativos dentro do escopo das ciências sociais, fortalecendo o espaço reflexivo neste campo através das postulações de que teoria e método não se separam, mas se complementam.

\section{Referências}

BECKER, Howard S. Métodos de pesquisa em Ciências Sociais. São Paulo: Hucitec, 1993.

BENEDICTO, Samuel Carvalho de; BENEDICTO, Gideon Carvalho de; SITEG, Carlos Maciel; ANDRADE, Gustavo em administraçâao e organizaç̧ôes: uma análise de suas limitaç̧̄oes e possibilidadades. Revista Economia \& Gestão. v.12 n.30, set./dez. 2012

BONI, Valdete; QUARESMA, Silvia Jurema. Aprendendo a entrevistar: como fazer entrevista em Ciências Sociais. Em Tese. V. 2, N. 1 (3), pp. 68-80, Janeiro-Julho, 2005.

BOURDIEU, Pierre. O poder simbólico. Rio de Janeiro: Bertrand Brasil, 1998.

BOURDIEU, Pierre. A miséria do mundo. Petrópolis, RJ: Vozes, 1997.

BOURDIEU, Pierre. Razões práticas - sobre a teoria da ação. Campinas/São Paulo: Papirus Editora, 1996.

BOURDIEU, Pierre. A ilusão biográfica. In: AMADO, Janaína e FERREIRA, Marieta de Moraes. Usos e abusos da

DELORY-MOMBERGER, Christine. Abordagens metodológicas na pesquisa biográfica. Revista Brasileira de Educação. v.17 n.51, set/dez. 2012.

GIL, Antonio Carlos. Entrevista. In: Métodos e Técnicas de Pesquisa Social. 6. ed. São Paulo: Atlas, 2008.

GUÉRIOS, Paulo Renato. $O$ estudo de trajetórias de vida nas ciências sociais: trabalhando com as diferenças de escalas. Campos. v.12 n.1, pp. 9-29, 2011.

GÜNTHER, Hartmut. Pesquisa Qualitativa Versus Pesquisa Quantitativa: Esta É a Questão?. Psicologia: Teoria e Pesquisa, Vol. 22 n. 2, pp. 201-210, Mai-Ago, 2006

GOLDENBERG, Mírian. A arte de pesquisar: como fazer pesquisa qualitativa em Ciências Sociais. Rio de Janeiro: Record, 2004.

MARTINS, Heloísa Helena T. de Souza. Metodologia qualitativa de pesquisa. Educação e pesquisa. v.30 n.2, pp. 289-300, mai/ago. 2004

MATTOS, Valéria de Bettio. Entrevista biográfica: uma possibilidade de análise qualitativa de trajetórias educacionais e profissionais de jovens egressos do ensino superior. Investigação Qualitativa em Educação. V. 2, p.

MILLS, C. Wright. A imaginação Sociológica. Rio de Janeiro: Zahar, 1980

MINAYO, Maria Cecília de Souza (org.). Pesquisa Social: Teoria, método e criatividade. 18 ed. Petrópolis: Vozes,

NICO, Magda. Viragem e ilusão biográfica: estratégias metodológicas alternativas para abordar a reflexividade e a temporalidade. In: VII Congresso Português de Sociologia. 2012, Universidade de Porto, Portugal,

Rh REVISTA SOCIAIS \& HUMANAS - VOL. 32 / No 3 - 2019
OLIVEIRA, Marinalva de Jesus; DEMBA, Azinaide Preciosa Mendes Baldaia; EMMENDOERFER Magnus Luiz; GODOI, Christiane Kleinübing. História oral e o método biográfico: congruências, diferenças e potencialidades
de utilização no campo da administraçăa. In: IV Encontro de Ensino e Pesquisa em Administração e Contabilidade. 2013, Brasilia/DF, 2013, p. 01-16.

QUIVY, Raymond; CAMPENHOUDT, Luc Van. Manual de Investigação em Ciências Sociais. Lisboa: Gradiva, 2005. ROGERS, Carl R. Psicoterapia e Consulta Psicológica. 2ª Ed. Santos: Martins Fontes, 1973.

SOUZA, Kellcia Rezende; KERBAUY, Maria Tereza Miceli. Abordagem quanti-qualitativa: superação da dicotomia quantitativa-qualitativa na pesquisa em educação. Educaçăo e Filosofia, v.31, n.61, p. 21-44, Jan-Abr, 2017. 